'Departamento de Pesquisa, Instituto Agronômico de Pernambuco (IPA), Av. General San Martin, 1371, Bongi, CEP 50761-000, Recife, PE, Brasil

2Departamento de Assistência Técnica e Extensão Rural, Instituto Agronômico de Pernambuco (IPA), Recife, PE, Brasil ${ }^{3}$ Secretaria de Agricultura e Reforma Agrária do Estado de Pernambuco, Recife, PE, Brasil

${ }^{4}$ Departamento de Educação

Profissional do Instituto Agronômico de Pernambuco (IPA), Recife, PE, Brasil ${ }^{5}$ Departamento de Apoio Técnico, Instituto Agronômico de Pernambuco (IPA), Recife, PE, Brasil

${ }^{6}$ Escritőrio Regional de Moreno, Instituto Agronômico de Pernambuco (IPA), Moreno, PE, Brasil

*autor correspondente

凶acarmem68@yahoo.com.br

\title{
Diagnóstico e planejamento: uma análise sistêmica das propriedades rurais no assentamento Timbó no município de Moreno, PE
}

\author{
Diagnosis and planning: a systemic analysis of the rural \\ properties in the settlement of Timbó in the municipality of \\ Moreno, State of Pernanbuco
}

Anália Carmem Silva de Almeida ${ }^{*}$, Danusa Rodrigues do Nascimento Correia de Araújo², Ana Lúcia de Lyra Guimarães ${ }^{3}$, Cleide Miriam de Sá Portela ${ }^{4}$, Gilvan Paes de Lira Júnior², Antônio Alves da Fonseca Barros ${ }^{5}$, Caio Campos Imperiano ${ }^{6}$, Denise de Santana Silva ${ }^{6}$

RESUMO: A utilização de diferentes metodologias de estudo sobre uma mesma temática têm resultado, invariavelmente, em diagnósticos cujos parâmetros dão margem às muitas interpretações, o que, do ponto de vista da ciência, não garante a credibilidade necessária. No âmbito das avaliações dos sistemas produtivos agrários, divergem as metodologias quanto ao grau de estruturação das ferramentas de levantamento de dados utilizadas. A metodologia Diagnóstico e Planejamento-D\&P é uma importante ferramenta para análise, avaliação e redesenho de sistemas produtivos agrários. No diagnóstico realizado no assentamento situado no município de Moreno, foram entrevistados 41 agricultores de base familiar. Foi identificado que as unidades produtivas do assentamento praticam a policultura, cujas espécies, em sua maioria, servem para consumo próprio das famílias do assentamento; apresentam não conformidades ambientais (ausência de área de reserva legal e de preservação permanente) em relação ao Código Florestal; sistemas de produção com uso de tecnologias diversas e inexistência de práticas de conservação do solo. O sistema produtivo geral do assentamento foi classificado como misto, caracterizado pela predominância da produção agrícola acompanhada, em seguida, em menor escala, pela pecuária. Observou-se ainda o uso de agrotóxicos, prática de queimadas, etc., nas propriedades do assentamento.

PALAVRAS-ChaVe: Metodologia D\&P, agroecossistema.
ABSTRACT: The use of different methodologies to study the same theme have invariably resulted in diagnostic parameters that give rise to many interpretations that, from the standpoint of science, do not assure the necessary credibility. As part of the evaluation of agricultural production systems, the methodologies differ in the degree of structuring the data collection tools used. The Diagnosis and Planning - D\&P methodology is an important tool for the analysis, evaluation and redesign of agricultural production systems. In the diagnosis carried out at a settlement located in the municipality of Moreno, 41 family-based farmers were interviewed. It was possible to identify that the production units of the settlement used mixed farming, whose species serve their own families' needs in the settlement; present environmental noncompliance (absence of legal reserve and permanent preservation areas) related to the Forest Code; production systems with the use of various technologies; and lack of soil conservation practices. The settlement's general production system was classified as mixed, characterized by the predominance of agricultural production accompanied subsequently, to a lesser extent, by livestock. It was also possible to observe the use of pesticides, burning practices, etc., in the properties of the settlement.

KEYWORDS: D\&P methodology, agroecosystems. 


\section{Introdução}

A metodologia Diagnóstico e Planejamento (D\&P), também conhecida como Diagnóstico e Desenho (D\&D), foi desenvolvida pelo International Centre for Research in Agroforestry - ICRAF (RAINTREE, 1987), sendo uma importante ferramenta de diagnóstico que pode ser usada quando se pretende trabalhar processos de transição agroecológica de um sistema produtivo de base não agroecológica.

Caporal e Costabeber (2004 apud ZONIN, 2007), define a transição agroecológica como o processo gradual de troca através do tempo nas formas de manejo e gestão dos agroecossistemas, tendo como meta a passagem de sistemas de produção "tradicionais" ou "convencionais" a outros sistemas de produção que incorporem princípios, métodos e tecnologias "de base ecológica" (de um processo de ecologização dinâmico, contínuo e crescente através do tempo, e sem ter um momento final determinado). Este processo de ecologização implica, não somente, maior racionalização produtiva, mas também numa mudança de atitudes e valores dos atores sociais em relação ao manejo à conservação do meio ambiente.

Conforme Embrapa (1998), o D\&P constitui um método interativo, participativo, dinâmico, de visão multidisciplinar e sistêmica. Ele considera a unidade produtiva e suas interrelações, busca ações integradas da pesquisa, da extensão rural e do próprio produtor e cria ambiente adequado para o desenvolvimento agroflorestal de forma ordenada. Este método "D\&P" (ou "D\&D") se processa através de: a) caracterização de comunidades, visando facilitar o processo de discussão com agentes institucionais locais; b) caracterização de propriedades, identificando sistemas de utilização da terra (SUTs), seus problemas e limitações; c) planejamento de propostas tecnológicas como alternativa de melhoria dos sistemas tradicionais. A última etapa do método contempla a priorização das propostas frente aos recursos disponíveis.

Segundo Moraes (1998), a ferramenta D\&D possui as seguintes etapas: pré-diagnóstico (planejamento do reconhecimento da área); diagnóstico (levantamento e análise das informações da área); desenho da tecnologia (identificação das tecnologias possíveis); avaliação e redesenho da tecnologia (classificação da adequabilidade das tecnologias propostas); planejamento (sistematização de resultados e revisão do estágio do conhecimento); e implementação (validação do diagnóstico e desenho e disponibilização do modelo como unidade de aprendizagem coletiva ou sistema de referência). O D\&P (ou D\&D) pode ser usado associado com as ferramentas do Diagnóstico Rural Participativo (DRP), como, por exemplo, a entrevista semiestruturada.

Verdejo (2007) destaca que a entrevista semiestruturada consiste num importante instrumento do DRP e de análise da realidade local em conjunto com a comunidade, sendo este DRP um conjunto de técnicas e ferramentas que permite que as comunidades façam o seu próprio diagnóstico e, a partir daí, comecem a autogerenciar o seu planejamento e desenvolvimento, compartilhando experiências e conhecimentos, a fim de melhorar as suas habilidades de planejamento e ação.

A avaliação de estratégias de desenvolvimento e sustentabilidade em assentamentos rurais, à luz dos preceitos da agroecologia, demonstra, ainda, certo grau de subjetividade, carecendo de maior embasamento científico e metodologias apropriadas para a sistematização de seus resultados assim como de métodos de mensuração eficientes e eficazes para avaliação quantitativa e qualitativa da produção e produtividade agropecuária. Portanto, com este trabalho, espera-se contribuir no avanço desta realidade no que diz respeito ao estado da arte do conhecimento agroecológico no Estado de Pernambuco.

\section{Material e Métodos}

\section{Área de estudo: O assentamento Timbó}

Trata-se de uma área de 206,3 hectares localizada no município de Moreno, na Região Metropolitana do Recife, no Estado de Pernambuco, nas coordenadas geográficas $08^{\circ} 06.778^{\prime} \mathrm{S}$ e $35^{\circ} 09.985^{\prime} \mathrm{W}$. Neste assentamento, foram instaladas 53 famílias, com parcela em torno de 3,89 ha, para cada uma. A ocupação, realizada pelo Movimento dos Trabalhadores - MT, majoritariamente por moradores e ex-trabalhadores da usina, ocorreu em 1997, sendo a imissão de posse realizada pelo INCRA em 1999.

O município de Moreno possui um número significativo de assentamentos da reforma agrária - 13 , sendo que a maioria das famílias assentadas tem raízes no próprio município. Dessa forma, crê-se que o processo organizacional foi facilitado, culminando na existência de um Conselho de Desenvolvimento Rural bastante atuante. Nessas reuniões, são tratados assuntos de interesses comuns, contando com a participação de representações do poder Público Municipal e instituições diversas.

No âmbito produtivo, no assentamento Timbó predominam os cultivos de espécies frutíferas, com destaque para coco e banana, embora se observe, ainda, o cultivo da cana-de-açúcar para fornecimento a uma usina próxima. Constatam-se, também, cultivos disseminados de culturas para subsistência - milho, feijão e mandioca -, e se comercializam apenas os excedentes, notadamente no comércio local. O uso da mão de obra é predominantemente familiar.

Entre as principais dificuldades observadas (para a produção), destacam-se a topografia acidentada, em vários trechos; a pequena disponibilidade de recursos hídricos em determinadas áreas de cultivo; a falta de acesso às tecnologias modernas de produção. No que tange à comercialização, há de se registrar a precariedade dos acessos, notadamente no período chuvoso, que torna o escoamento bastante difícil.

O acesso às políticas públicas é facilitado pela informação, no qual o Conselho Municipal de Desenvolvimento Rural Sustentável-CMDRS tem um papel fundamental, destacando-se o Programa Bolsa Família e o Programa Nacional de Fortalecimento da Agricultura Familiar-PRONAF.

O D\&P, por seu turno, foi realizado durante o segundo semestre de 2010. Sua execução foi solicitada pelo Instituto de Terras de Pernambuco-Iterpe e teve como objetivo conhecer a realidade local, tendo em vista uma futura proposta de início do processo de transição agroecológica nas unidades produtivas familiares através de ações de extensão rural e pesquisa. 
Nas unidades produtivas de agricultura familiar do assentamento, foram aplicadas as seguintes fases do D\&P: caracterização de comunidades e caracterização de propriedades, identificando sistemas de utilização da terra (SUTs), seus problemas e limitações. Estas fases no D\&D são denominadas respectivamente de pré-diagnóstico e diagnóstico.

Considerando que a metodologia D\&P deixa em aberto (a critério do pesquisador) a forma de coleta de dados, foi utilizada entrevista semiestruturada (ferramenta do DRP), por ser uma das mais adequadas para compor a forma de coleta de dados para o presente trabalho. A entrevista semiestruturada foi composta de vinte questões e aplicada a 41 pessoas, todas elas proprietárias de lotes do assentamento.

Foi procedida a caracterização ambiental das propriedades (adequação à legislação ambiental e tratamento dado ao lixo), condições de conservação do solo, práticas de manejo dos sistemas de produção utilizados na propriedade, caracterização dos sistemas de produção sob a ótica tecnológica e socioeconômica dos entrevistados (nível de renda e inclusão em políticas públicas).

Esses indicadores foram escolhidos porque a abordagem agroecológica (a qual é o eixo estruturador da nova Política Nacional de Assistência Técnica e Extensão Rural- PNATER de uma unidade produtiva) pressupõe que ela mesma seja pesquisada e trabalhada, considerando as suas dimensões ecológica, social, econômica, cultural, política e ética. Assim, no processo da pesquisa empregado, as questões da entrevista semiestruturada foram elaboradas procurando, ao máximo, envolver tais indicadores.

\section{Resultados e Discussão}

\section{Código florestal}

Percebe-se que, conforme os dados amostrados na Tabela 1, 24,39\% das propriedades não possuem área de reserva legal, conforme determina o Código Florestal Brasileiro (BRASIL..., 1965). Foi detectado que 68,29\% destas propriedades não possuem área de preservação permanente-APP e $34,15 \%$ dos proprietários realizam a prática de queimada no solo como método de limpeza da área.

Constata-se, segundo a Tabela 2, que 48,78\% do lixo das propriedades é queimado e 14,63\% é enterrado.

\section{Conservação do solo}

Verifica-se, na Tabela 3, que, das propriedades visitadas, 29,27\% apresentam visivelmente solo com matéria orgânica, $48,78 \%$ possui solo compactado e $48,78 \%$ demonstrou processos erosivos presentes na área.

\section{Controladores químicos}

Conforme a Tabela 4, o uso de agrotóxicos nas unidades produtivas é alto $(60,97 \%)$ sendo constatada a sua aplicação sem o uso de equipamento de proteção individual-EPI, sem a observação dos períodos de carência, da dosagem adequada e sem a capacitação dos agricultores para utilização desses produtos.
Verifica-se, também, que a maior parte da área do assentamento $(73,17 \%)$ realiza plantio em área de declive, $24,39 \%$ das propriedades da área usam adubação química, 24,39\% dessas propriedades utilizam adubo orgânico e 17,07\% usam concomitantemente adubações químicas e orgânicas. Estes dados sugerem a possibilidade de um reordenamento da produção (aumento da área para o plantio de culturas silvícolas, prática da apicultura e de cultivos agrícolas adequados à declividade existente no local) e utilização de práticas de conservação do solo (plantio em curvas de nível, em cordões de contorno, terraceamento, etc.).

\section{Equipamentos}

A Tabela 5 mostra que nas propriedades do assentamento Timbó foram encontradas as seguintes tecnologias de uso no processo produtivo: $73,16 \%$ utilizam carro de mão, estrovenga e enxada e $26,84 \%$ possuem sistema de irrigação, pulverizador manual, implemento de tração animal, cocheira e aviário.

A Tabela 6 revela como minifúndios as unidades produtivas do assentamento Timbó.

De acordo com a Tabela 7, observa-se que as unidades produtivas praticam a policultura, com lavouras de subsistência e de valor comercial.

Tabela 1. Adequação à legislação ambiental das unidades produtivas visitadas no assentamento Timbó em Moreno, PE.

\begin{tabular}{cccc}
\hline $\begin{array}{c}\text { Categorias } \\
\text { das } \\
\text { respostas }\end{array}$ & $\begin{array}{c}\text { Propriedades com } \\
\text { áreas de reserva legal } \\
(\boldsymbol{\%})\end{array}$ & $\begin{array}{c}\text { Propriedades } \\
\text { com APP } \\
(\boldsymbol{\%})\end{array}$ & $\begin{array}{c}\text { Prática de } \\
\text { queimada } \\
(\boldsymbol{\%})\end{array}$ \\
\hline Sim & 4,88 & 4,88 & 7,32 \\
Não & 24,39 & 68,29 & 34,15 \\
Não & 70,73 & 26,83 & 58,53 \\
reponderam & & & \\
\hline
\end{tabular}

Tabela 2. Tratamento dado ao lixo pelas unidades produtivas visitadas no assentamento Timbó em Moreno, PE.

\begin{tabular}{lc}
\hline Tratamento dado ao lixo & Total $(\boldsymbol{\%})$ \\
\hline Queimado & 48,78 \\
Enterrado & 14,63 \\
Jogado aleatoriamente & 9,76 \\
Entregue para reciclagem & 2,44 \\
Não responderam & 24,39 \\
\hline
\end{tabular}

Tabela 3. Avaliação das condições de conservação do solo das unidades produtivas visitadas no assentamento Timbó em Moreno, PE.

\begin{tabular}{|c|c|c|c|}
\hline \multirow{2}{*}{$\begin{array}{c}\text { Algumas } \\
\text { características do } \\
\text { solo do assentamento }\end{array}$} & \multicolumn{3}{|c|}{ Total } \\
\hline & $\operatorname{Sim}(\%)$ & Não (\%) & Não responderam (\%) \\
\hline Com matéria orgânica & 29,27 & 24,39 & 46,34 \\
\hline Compactado & 48,78 & 14,63 & 36,59 \\
\hline Com erosão & 48,78 & 21,95 & 29,27 \\
\hline
\end{tabular}


Tabela 4. Práticas fitossanitárias e de adubação realizadas nas unidades produtivas do assentamento Timbó em Moreno, PE.

\begin{tabular}{|c|c|c|c|c|c|}
\hline \multirow{2}{*}{ Categorias das respostas } & \multirow{2}{*}{ Utiliza agrotóxico (\%) } & \multicolumn{3}{|c|}{ Utiliza adubação (\%) } & \multirow{2}{*}{ Realiza plantio em área de declive (\%) } \\
\hline & & Química & Orgânica & Química e orgânica & \\
\hline Sim & 60,97 & 24,39 & 24,39 & 17,07 & 73,17 \\
\hline Não & 12,20 & \multicolumn{3}{|c|}{9,76} & 2,44 \\
\hline Não responderam & 26,83 & \multicolumn{3}{|c|}{24,39} & 24,39 \\
\hline
\end{tabular}

Tabela 5. Uso de implementos e equipamentos nas unidades produtivas do assentamento Timbó em Moreno, PE.

\begin{tabular}{lc}
\hline \multicolumn{1}{c}{ Implementos agropecuários encontrados } & Total $(\boldsymbol{\%})$ \\
\hline Carro de mão, estrovenga e enxada. & $73,16 \%$ \\
Sistema de irrigação, pulverizador manual, & $26,84 \%$ \\
implemento de tração animal, cocheira, aviário. & \\
\hline
\end{tabular}

Tabela 6. Caracterização fundiária das unidades produtivas do assentamento Timbó em Moreno, PE.

\begin{tabular}{lc}
\hline Áreas das propriedades & Total $(\boldsymbol{\%})$ \\
\hline 1 a 2 ha & 2,44 \\
2 a 4 ha & 90,24 \\
Não responderam & 7,32 \\
\hline
\end{tabular}

Tabela 7. Caracterização das culturas agrícola e florestais encontradas nas propriedades do assentamento Timbó em Moreno, PE.

\begin{tabular}{cl}
\hline $\begin{array}{c}\text { Intervalo de classe } \\
\text { de produtores(as) }\end{array}$ & \multicolumn{1}{c}{ Culturas praticadas } \\
\hline $1 \%$ a $20 \%$ & $\begin{array}{l}\text { Goiaba, caju, jaca, fava, limão, cana-de-açúcar, } \\
\text { mamão, amendoim, batata-doce, maracujá, } \\
\text { sabiá, pepino, cará, inhame, coentro, quiabo, } \\
\text { seriguela, abacate, laranja. }\end{array}$ \\
& Graviola, manga, feijão, acerola e maxixe. \\
$40 \%$ a $40 \%$ & Coco, banana e macaxeira. \\
\hline
\end{tabular}

Tabela 8. Tipos de criações pecuárias existentes nas propriedades do assentamento Timbó em Moreno, PE.

\begin{tabular}{lc}
\hline Sistemas de produção & Propriedade $(\%)$ \\
\hline Bovinos & 4,88 \\
Caprinos & 9,76 \\
\hline Ovinos & 2,44 \\
Suínos & 2,44 \\
Aves & 7,32 \\
Peixes & 2,44 \\
\hline Equinos & 4,88 \\
Asininos & 2,44 \\
\hline Não criam animais & 63,40 \\
\hline
\end{tabular}

Tabela 9. Caracterização socioeconômica (renda e inclusão em políticas públicas) dos(as) agricultores(as) do assentamento Timbó em Moreno, PE.

\begin{tabular}{lccc}
\hline \multicolumn{1}{c}{ Renda } & Total (\%) & Fonte de renda & Total (\%) \\
\hline $\begin{array}{l}\text { Menos de um salário } \\
\text { mínimo }\end{array}$ & 24,39 & INSS & 53,66 \\
$\begin{array}{l}\text { Um salário mínimo } \\
\begin{array}{l}\text { Maior do que um salário } \\
\text { mínimo a menor de dois }\end{array}\end{array}$ & 17,07 & Chapéu de palha & 2,44 \\
$\begin{array}{l}\text { salários mínimos } \\
\text { 2 salários mínimos }\end{array}$ & 9,76 & Bolsa família & 21,94 \\
Não responderam & 12,19 & Bolsa escola & 2,44 \\
\hline
\end{tabular}

\section{Sistemas de produção animal}

A Tabela 8 demonstra os tipos de criação dos assentamentos. Segundo os produtores, os animais servem para o abastecimento dos assentados e o excedente é comercializado.

\section{Renda}

A Tabela 9 mostra que 24,39\% têm renda familiar menor do que um salário mínimo, 36,59\% ganham até um salário mínimo, 17,07\% possuem renda maior do que um salário mínimo e menor que dois salários mínimos e 9,76\% ganham mensalmente dois salários mínimos. Foi ainda constatado que, em relação aos programas assistenciais dos Governos Federal (Crédito Agrícola, Bolsa Família e Bolsa Escola) e Estadual (Programa Chapéu de Palha), 53,66\% são beneficiários do INSS, $19,51 \%$ são atendidos pelo crédito agrícola, 2,44\% são beneficiários do Programa Chapéu de Palha, 21,94\% são atendidos pelo Bolsa Família e 2,44\% são atendidos pelo Bolsa Escola.

\section{Conclusões}

Constatou-se que no assentamento Timbó predomina um sistema de produção misto caracterizado pela predominância da produção agrícola (com policultivos) acompanhada, em seguida, em menor escala, pela pecuária. Verificou-se também a presença de problemas fitossanitários (pragas e doenças) nas áreas de produção, reduzida área de pasto para rebanhos e que os produtores não usam ração para complementação da alimentação dos animais. Ainda foram detectados problemas de adequação ambiental das propriedades em relação ao Código Florestal (delimitação de áreas de reserva legal e de APP). 
Esta realidade sugere a possibilidade de um redesenho do sistema da produção, por meio do qual haja práticas de conservação do solo e cultivo de espécies adequadas às características topográficas do imóvel como algumas fruteiras e algumas espécies florestais. Tanto as espécies fruteiras como as florestais seriam úteis inclusive à introdução da atividade de apicultura no assentamento.

Verifica-se também que o assentamento possui facilidade de acesso e escoamento dos produtos aos mercados consumidores, pois se localiza próximo à Região Metropolitana do Recife. Os assentados possuem uma associação, há presença de mulheres como produtoras e comerciantes da produção; há acesso dos(as) assentados(as) às políticas públicas com algumas destas complementando a renda familiar. $\mathrm{Na}$ época da pesquisa, a associação enfrentava problemas relacionados à inadimplência com agentes de crédito rural.

A continuidade das atividades de assistência técnica e extensão rural no assentamento Timbó associada com as atividades de pesquisa poderão trazer ações que promovam, em conjunto com a comunidade local, a regularização ambiental da área (delimitação da área de reserva legal e de APP), o planejamento e execução de ações de redesenho dos sistemas da produção assim como o controle fitossanitário das culturas, o uso de práticas conservacionistas do solo, manejo adequado dos resíduos sólidos e intervenções que promovam o incremento de suporte forrageiro para os animais.

\section{Referências}

BRASIL. Ministério do Meio Ambiente. Lei no 4.771, de 15 de Setembro de 1965. Institui o Novo Código Florestal. Diário Oficial da República Federativa do Brasil, Brasília, DF, 16 set. 1965. Disponível em: <www.controleambiental.com.br/codigo_florestal. htm>. Acesso em: 07 jul. 2009.

EMBRAPA. Diagnóstico e planejamento de sistemas agroflorestais na microbacia "Rio Claro" no município de São Mateus do Sul, PR. Colombo: Embrapa Floresta, 1998. 48 p.

MORAES, C. A. Manejo integrado da bacia hidrográfica do Almada, bioma Mata Atlântica: treinamento em sistemas agroflorestais. Ilhéus: SEPLANTEC/SEI EMBRAPA-CNPC/ RAMA/CEPLAC, 1998. $51 \mathrm{p}$.

RAINTREE, J. B. D \& D user's manual: na introduction to agroforestry diagnosis anddesign. Nairobi: ICRAF, 1987. 110 p.

VERDEJO, M. E. Diagnóstico rural participativo: guia prático DRP. Brasília: MDA- Secretaria de agricultura Familiar, 2007. 62 p.

ZONIN, W. J. Transição agroecológica: modalidades e estágios na região metropolitana de Curitiba. 2007. 278 f. Tese (Doutorado em Ruralidade, Ambiente e Sociedade)-Universidade Federal do Paraná, Curitiba, 2007. 